\title{
Polyarticular Ochronotic Arthritis: A Case Report
}

\author{
Marco Di Marco Silvia Elena De Martinis Marcello Truzzi \\ Roberto Viganò \\ Department of Rheumasurgery, ASST Pini-CTO Hospital, University Faculty of Medicine, \\ Milan, Italy
}

\section{Keywords}

Ochronotic arthropathy · Alkaptonuria · Ochronosis · Homogentisic acid · Polyarticular degeneration

\begin{abstract}
Alkaptonuria is an inherited disease due to the lack of homogentisic acid oxidase enzyme. The most common clinical presentations are a brownish-grey color of the sclera, dark skin, kidney stones, aortic calcifications, and ochronotic arthropathy. Ochronotic arthropathy is characterized by the accumulation of homogentisic acid in the connective tissue determining severe joint degeneration. We present the case of a woman affected by ochronosis since the age of 30 years. The patient showed a severe degeneration of the hip and knee joints bilaterally, associated with an important and painful functional limitation. Conservative care did not achieve good results. We performed bilateral cementless total knee arthroplasty and bilateral cementless total hip arthroplasty. We report satisfactory outcomes in terms of range of motion and pain control in a 6-year follow-up. Our approach to this pathology is the same we adopt with rheumatoid arthritis after our decennial experience. We suggest that prosthetic replacement represents a definitive way to treat ochronotic arthropathy.

(C) 2019 The Author(s)

Published by S. Karger AG, Basel
\end{abstract}




\section{Case Reports in Orthopedic Research}

\section{Introduction}

Ochronosis is a rare condition affecting the musculoskeletal system in patients with alkaptonuria [1]. Alkaptonuria is a disorder of homogentisic acid (HGA) related to an autosomal recessive mutation of the $H G A$ gene located on $3 q$ chromosome. The incidence of this rare disease is 1:25,000-100,000 [2]. Homogentisic acid, which is commonly produced during the metabolism of phenylalanine and tyrosine, accumulates in connective tissues and urine as a result of the deficit of the enzyme homogentisic acid oxidase in the kidney and liver [2, 3]. Alkaptonuria typically presents with a dark color of urine and pigment deposition among the sclera, hyaline cartilage, and tendons $[2,4,5]$.

The most common clinical presentations are a brownish-grey color of the sclera, dark skin, kidney stones, aortic calcifications, and ochronotic arthropathy. This type of pathology is characterized by the accumulation of dark pigments in the joint cartilage, resulting in a chronic flogistic process and secondly in an inflammatory arthritis $[4,5]$. The most commonly involved joints are the knee and hip, but also the vertebral column and shoulder can be affected by this progressive disease [6, 7]. We report the 7-year follow-up of a patient who underwent bilateral prosthetic replacements of the hip and knee joints.

\section{Case Presentation}

Our patient was a 50-year-old female affected by ochronosis since the age of 30 years. At the beginning, she was treated with NSAIDs, chloroquine, and tramadol by rheumatologists without good results. She came to our attention in 2004, referring important knee and hip pain and functional limitations persisting for more than 6 years.

The patient showed distinctive phenotypical features of alkaptonuria: an ochre color of the sclera, synovitic and arthritic degeneration of the hip and knee joints associated with a black pigmentation of the articular cartilage, and modifications on the dorsal and lumbar parts of the vertebral column.

Physical examination of the knees showed varus deformity and swelling, and a global pain around the knees was recorded, especially during mobilization, but no ligamentous laxity was observed. Right-knee range of motion was $5^{\circ}-5^{\circ}-100^{\circ}$, while the left knee showed a range of motion of $0^{\circ}-0^{\circ}-120^{\circ}$.

Physical examination of the hips showed a severe pain during acupressure and mobilization. Right-hip range of motion was $0^{\circ}-0^{\circ}-85^{\circ}$ in flexion/extension, $10^{\circ}-0^{\circ}-20^{\circ}$ in abduction/adduction, $15^{\circ}-10^{\circ}$ extra-/intrarotation. The left hip was aching, and its range of motion was $0^{\circ}-0^{\circ}-90^{\circ}$ in flexion/extension, $15^{\circ}-0^{\circ}-20^{\circ}$ in abduction/adduction, and $10^{\circ}-15^{\circ}$ extra-/intrarotation.

X-ray images of the two hips underlined a profile of arthritic degeneration associated with geodes and osteophytes (Fig. 1, 2). Moreover, radiological evaluation of both knees evidenced an advanced tricompartmental involvement, showing narrowing of the joint spaces, subchondral sclerosis, deformities of joint surfaces, and calcifications in the soft tissues (Fig. 3, 4). A CT scan performed to complete the diagnostic investigation of the hips evidenced severe deformities and irregularities of the joint surfaces (Fig. 5). The patient underwent uncemented 
right-knee arthroplasty in 2004 (Fig. 6), uncemented left-knee arthroplasty in 2006 (Fig. 7), uncemented right-hip arthroplasty in 2009, and uncemented left-hip arthroplasty in 2010 (Fig. 8). The surgical program started with the treatment of the most painful joint. No intraoperative and postoperative complications were observed during all surgical interventions.

The patient went through a good postoperative period and was able to perform all medical therapies and to manage the rehabilitation period without any trouble. We achieved satisfying results in terms of improvement of the range of motion, pain relief, and radiological follow-up at the end of the prosthetic replacement program (Table 1, Table 2).

Histological examinations of bone and soft tissues demonstrated classic findings such as multiple pigmented areas, reactive giant cells, a thickened inflamed synovium, and pigmented fibrocartilaginous tissue according to clinical diagnosis of Ochronosis (Fig. 9).

\section{Discussion}

Patients affected by ochronosis are usually asymptomatic until the 4th decade of life. This kind of arthropathy presents a really slow development connected to homogentisic acid deposition on the joint level. As known from the literature, the deposition of homogentisic acid is lower during young age due to a more effective renal elimination [8]. Anyway, initial treatment is always conservative and aimed at limiting the flogistic process by using anti-inflammatory drugs and eventually immunosuppressive drugs. Surgery can represent an effective alternative to treat cases associated to severe joint involvement and low pain control.

In the literature, many case reports about the surgical management of ochronosis describe joint replacement for the hip and knee [9]. The peculiarity of the presented case lies in a surgical treatment involving bilateral hip and knees joints. Therefore, the patient was approached following the same path chosen for patients affected by rheumatoid arthritis with severe and polyarticular degeneration. Authors' choice of uncemented implants is related to the decennial experience acquired in the surgical treatment of patients affected by rheumatoid arthritis.

\section{Conclusions}

Currently, there is no effective therapy or prophylactic treatment for alkaptonuric patients. Treatment is basically supportive and targeted to prevent or reduce the effects of ochronotic arthropathy [10]. Orthopedic surgeons should consider ochronosis in the differential diagnosis with other chronic inflammatory diseases associated with joint degeneration. Based on our evidence, ochronosis can be considered as chronic flogistic rheumatism. Therefore, our surgical approach to this pathology is similar to the one used in rheumatoid arthritis. In our opinion, prosthetic replacement, which shows excellent outcomes in terms of pain reduction and functional improvement, represents the definitive solution in case of advanced ochronotic arthropathy. Moreover, joint replacement shows excellent outcomes in patients with severe degenerative arthropathy connected to ochronosis. 


\section{Case Reports in Orthopedic Research}

Case Rep Orthop Res 2019;2:1-13
\begin{tabular}{l|l} 
DOI: $10.1159 / 000500236$ & $\begin{array}{l}\text { (c) 2019 The Author(s). Published by S. Karger AG, Basel } \\
\text { www.karger.com/cio }\end{array}$
\end{tabular}

Di Marco et al.: Polyarticular Ochronotic Arthritis: A Case Report

\section{Statement of Ethics}

All procedures followed were in accordance with ethical standards of the responsible committee on human experimentation (institutional and national) and with the Helsinki Declaration of 1964 and its later amendments. Informed consent was obtained from the patient for being included in this case report.

\section{Disclosure Statement}

The authors have no conflicts of interest to declare.

\section{References}

1 Harun M, Hayrettin Y, Serhat M, Cuneyt M, Firat F, Ufuk O. A rare cause of arthropathy: an ochronotic patient with black joints. Int J Surg Case Rep. 2014;5(8):554-7.

2 Aydoğdu S, Cullu E, Ozsoy MH, Sur H. Cementless total knee arthroplasty in ochronotic arthropathy: a case report with a 4-year follow-up. J Arthroplasty. 2000 Jun;15(4):539-43.

3 Araki K, Sudo A, Hasegawa M, Uchida A. Devastating ochronotic arthropathy with successful bilateral hip and knee arthroplasties. J Clin Rheumatol. 2009 Apr;15(3):138-40.

4 Wu K, Bauer E, Myung G, Fang MA. Musculoskeletal manifestations of alkaptonuria: A case report and literature review. Eur J Rheumatol. 2018 Nov;16:1-5.

5 Drakoulakis E, Varvitsiotis D, Psarea G, Feroussis J. Ochronotic arthropathy: diagnosis and management: a critical review. Am J Orthop (Belle Mead NJ). 2012 Feb;41(2):80-3.

6 Rathore FA, Ayaz SB, Mansoor SN. Ochronotic Arthropathy: Two Case Reports from a Developing Country. Clin Med Insights Arthritis Musculoskelet Disord. 2016 Feb;9:15-20.

7 Cebesoy O, Isik M, Subasi M, Kaya A, Bilgin F, Kaya O. Total hip replacement for an ochronotic patient: A technical trick. Am J Case Rep. 2014 Jan;15:27-30.

8 Hamdi N, Cooke TD, Hassan B. Ochronotic arthropathy: case report and review of the literature. Int Orthop. 1999;23(2):122-5.

9 Mazoochy H, Razi M. Knee and Hip Joint Replacement Surgery in a Patient with Ochronotic Arthropathy: surgical Tips. Arch Bone Jt Surg. 2018 Nov;6(6):577-81.

10 Gil JA, Wawrzynski J, Waryasz GR. Orthopedic Manifestations of Ochronosis: Pathophysiology, Presentation, Diagnosis, and Management. Am J Med. 2016 May;129(5):536.e1-6. 


\section{Case Reports in Orthopedic Research}

Case Rep Orthop Res 2019;2:1-13 www.karger.com/cio

Di Marco et al.: Polyarticular Ochronotic Arthritis: A Case Report

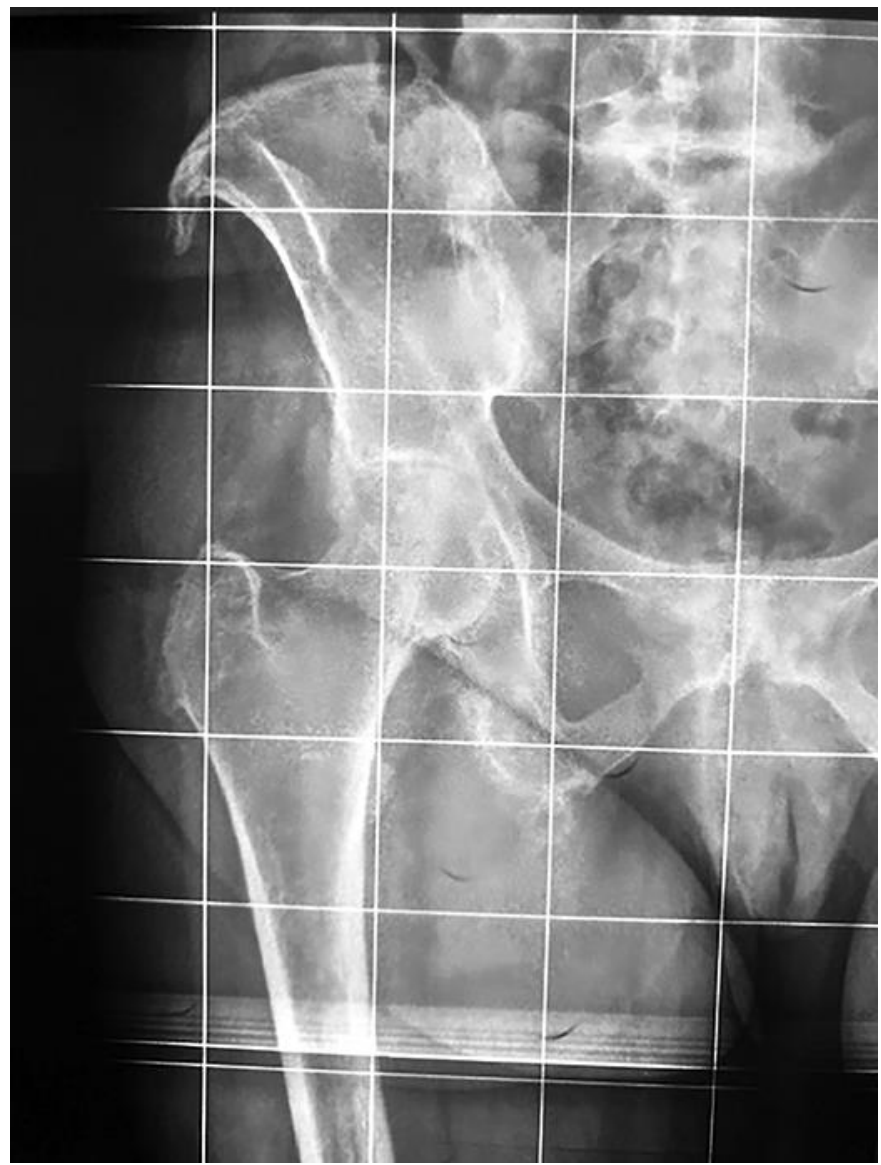

Fig. 1. Right-hip preoperatory X-ray. 


\section{Case Reports in Orthopedic Research}

Case Rep Orthop Res 2019;2:1-13

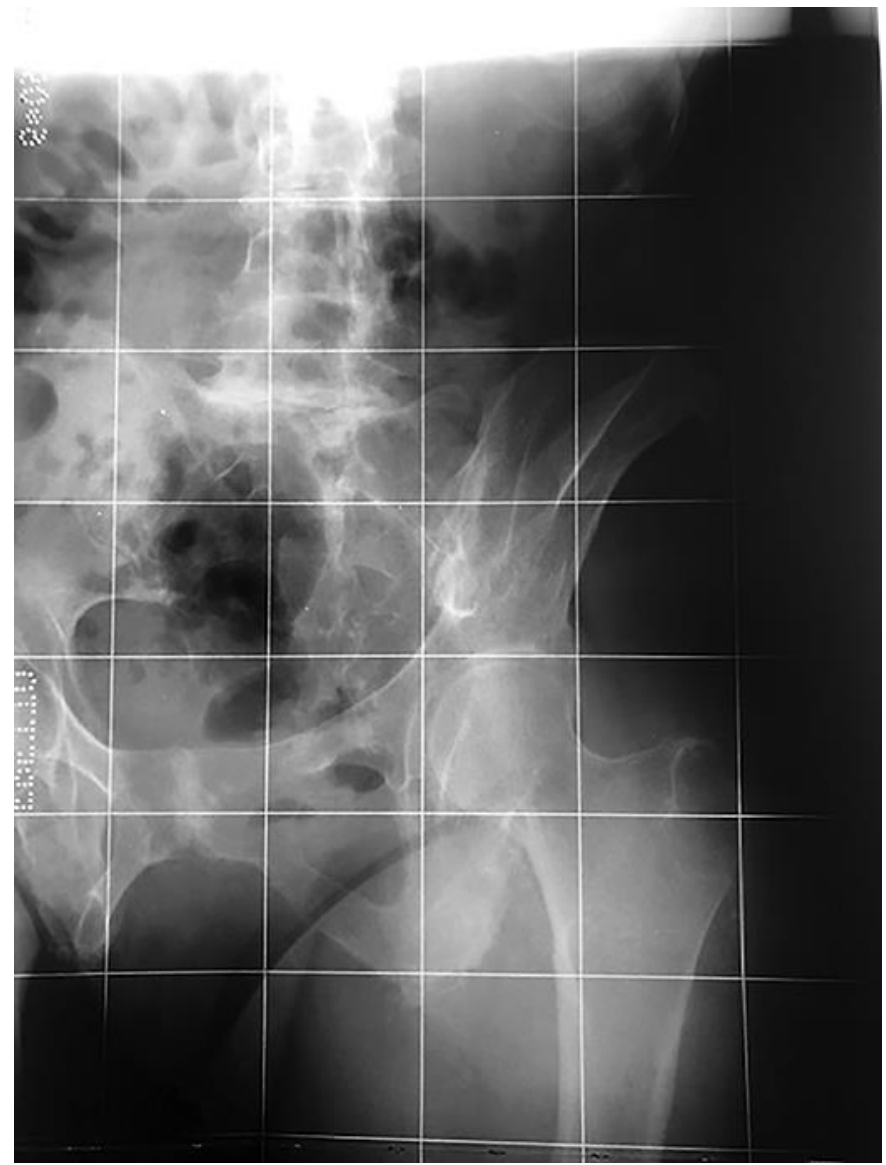

Fig. 2. Left-hip preoperatory X-ray. 


\section{Case Reports in Orthopedic Research}

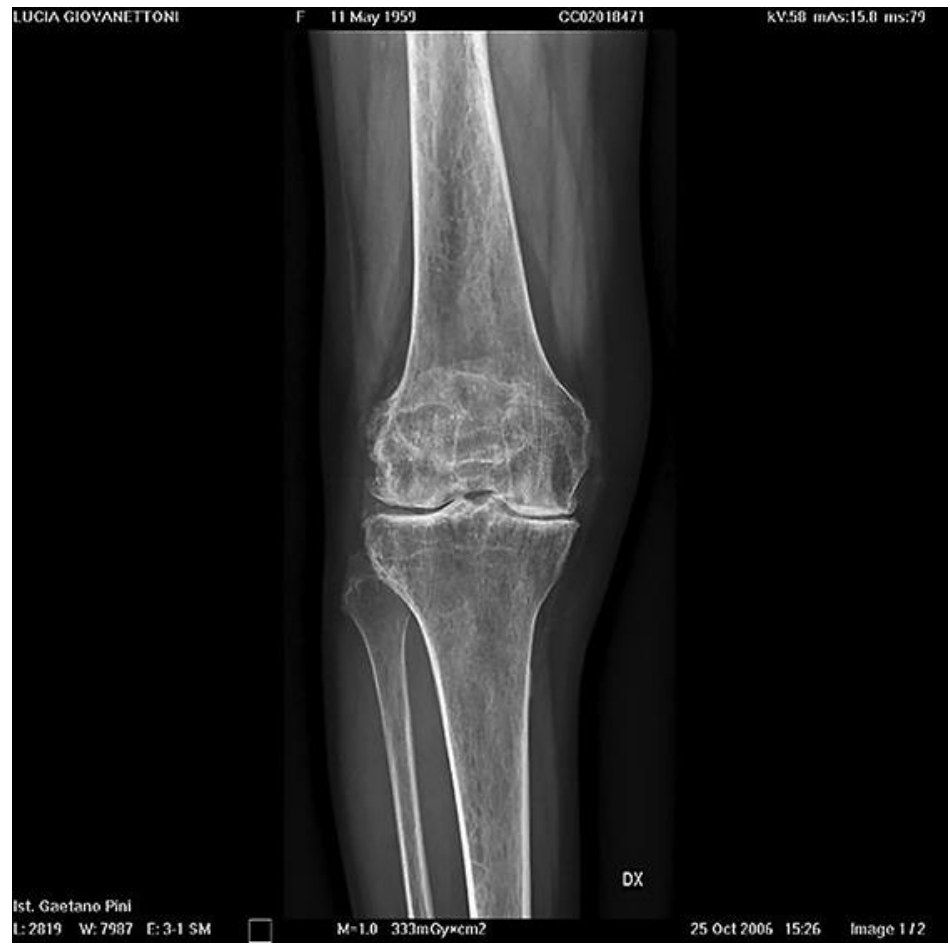

Fig. 3. Right-knee preoperative X-ray. 


\section{Case Reports in Orthopedic Research}

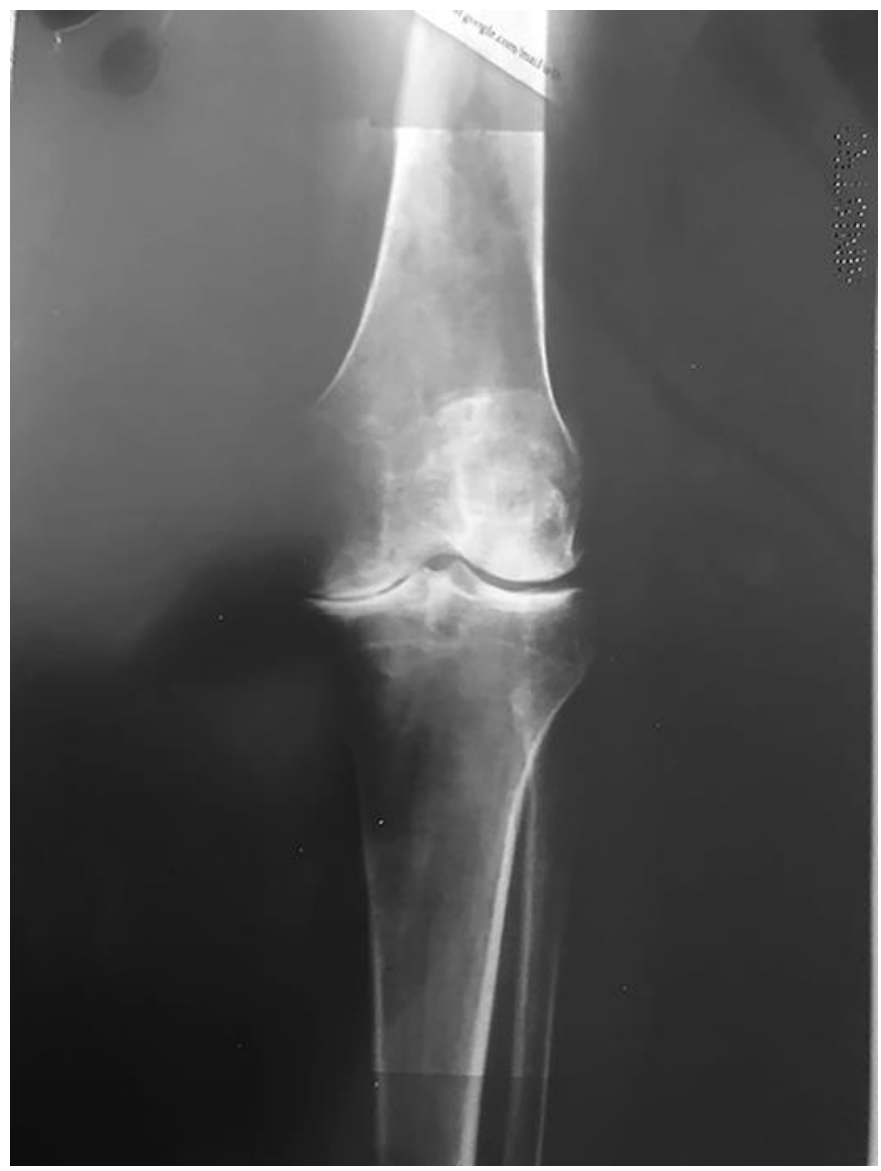

Fig. 4. Left-knee preoperative X-ray. 


\section{Case Reports in Orthopedic Research}

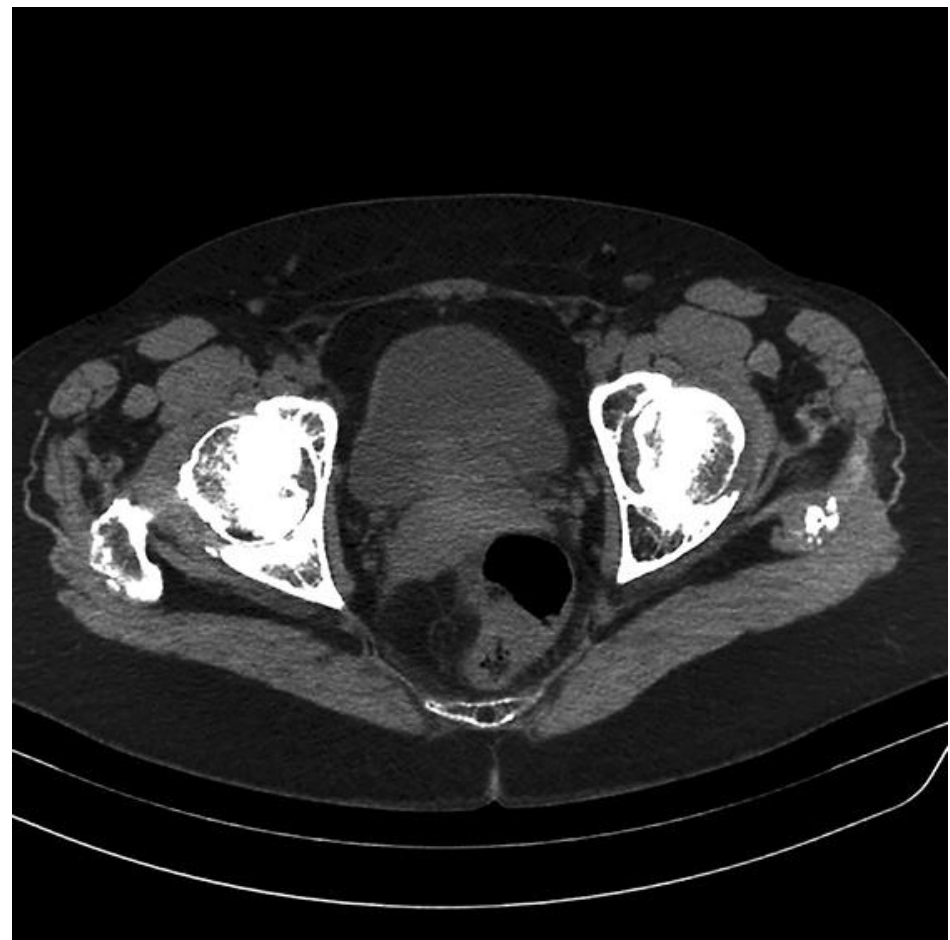

Fig. 5. Hip bone preoperative CT scan examination. 


\section{Case Reports in Orthopedic Research}

www.karger.com/cio

Di Marco et al.: Polyarticular Ochronotic Arthritis: A Case Report

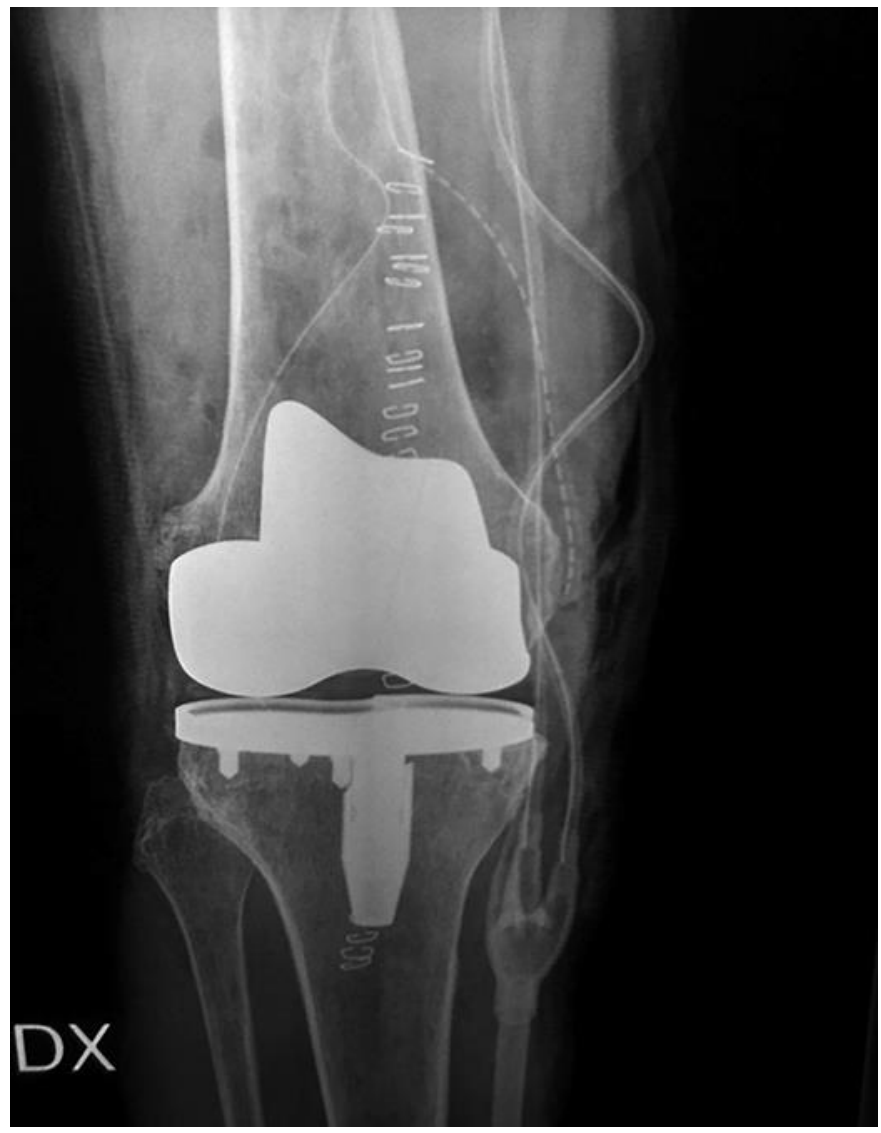

Fig. 6. Right-knee arthroplasty, postoperative X-ray. 


\section{Case Reports in Orthopedic Research}

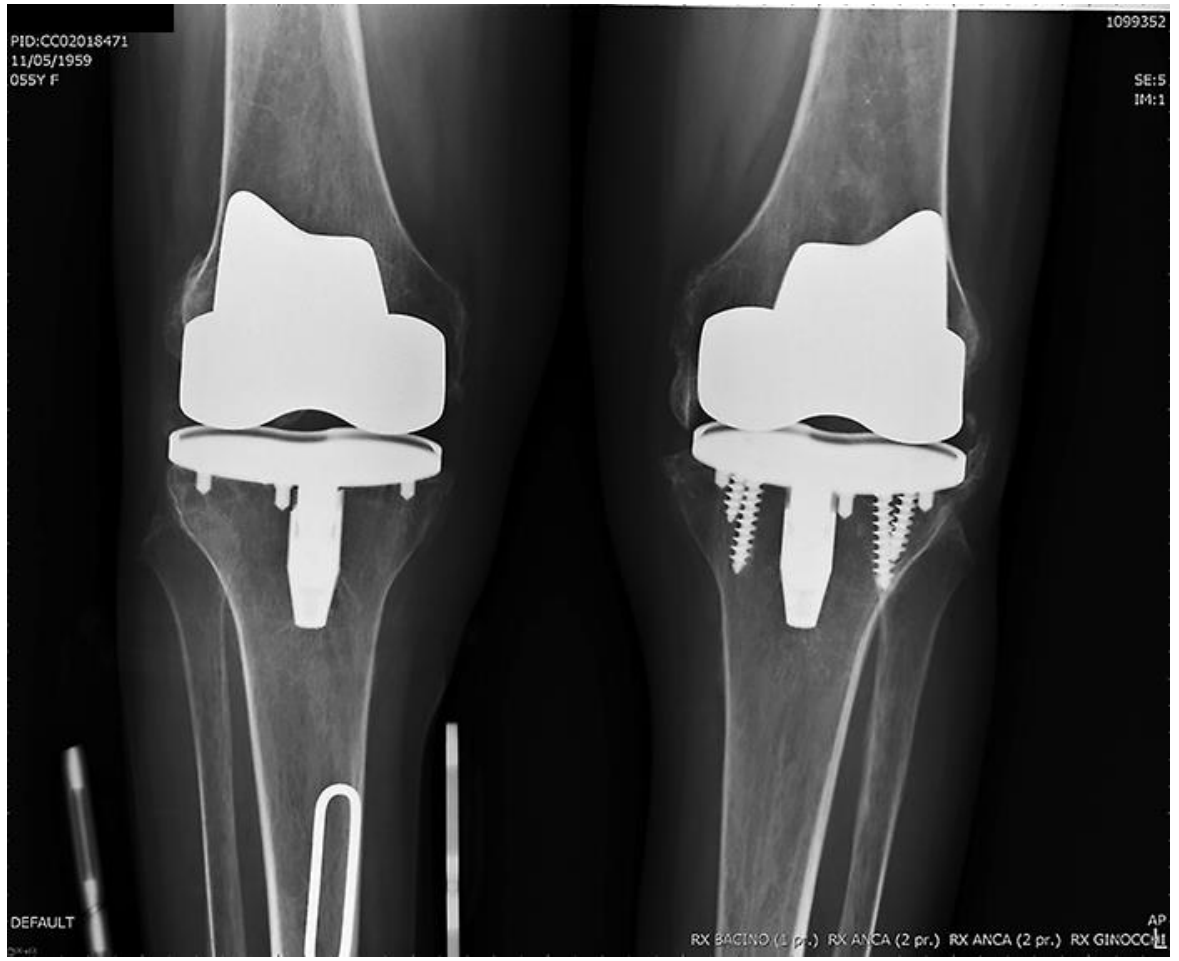

Fig. 7. Left-knee arthroplasty, postoperative X-ray. 


\section{Case Reports in Orthopedic Research}

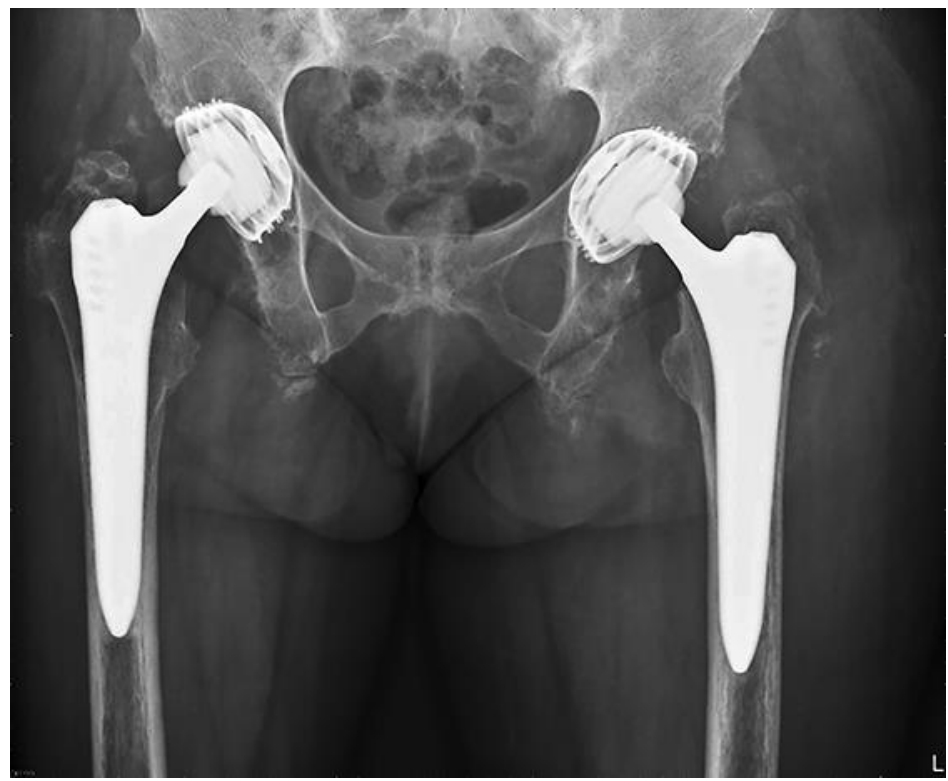

Fig. 8. Right- and left-hip arthroplasties X-ray.

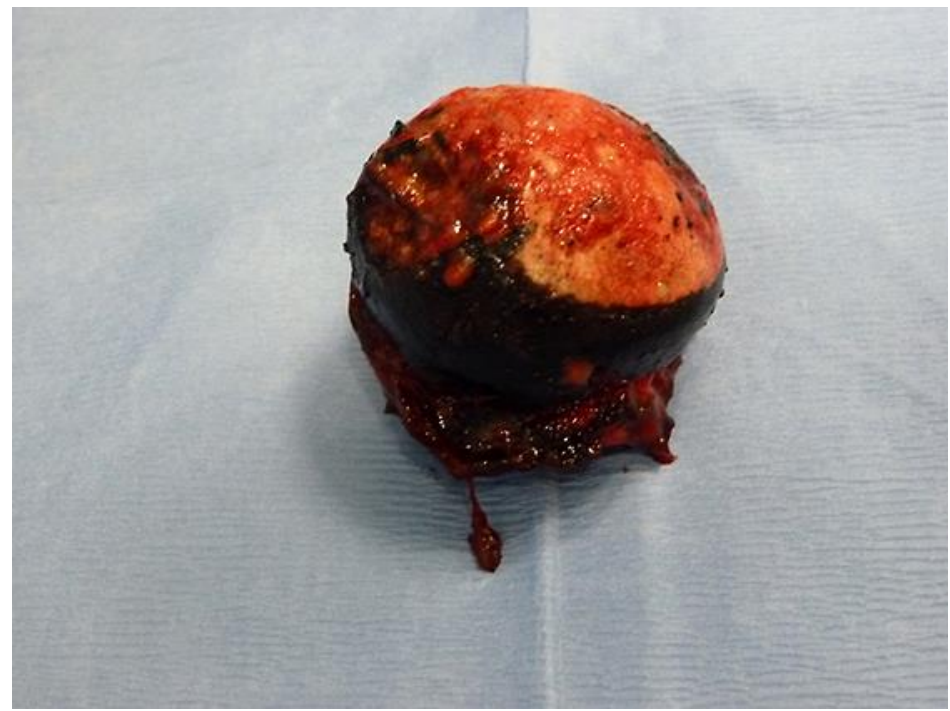

Fig. 9. Pigmented areas of the femoral head. 

Research

Di Marco et al.: Polyarticular Ochronotic Arthritis: A Case Report

Table 1. Postoperative range of motion of the knees

\begin{tabular}{ll} 
Left knee & $0^{\circ}-0^{\circ}-120^{\circ}$ \\
Right knee & $0^{\circ}-0^{\circ}-110^{\circ}$ \\
\hline
\end{tabular}

\begin{tabular}{ll} 
Left knee & $0^{\circ}-0^{\circ}-120^{\circ}$ \\
Right knee & $0^{\circ}-0^{\circ}-110^{\circ}$ \\
\hline
\end{tabular}

Table 2. Postoperative range of motion of the hips

\begin{tabular}{llll}
\hline & Flex/Ext & Abd/Add & Er/Ir \\
\hline Left hip & $0^{\circ}-0^{\circ}-100^{\circ}$ & $35^{\circ}-0^{\circ}-20^{\circ}$ & $25^{\circ}-0^{\circ}-15^{\circ}$ \\
Right hip & $0^{\circ}-0^{\circ}-95^{\circ}$ & $30^{\circ}-0^{\circ}-20^{\circ}$ & $20^{\circ}-0^{\circ}-15^{\circ}$ \\
\hline
\end{tabular}

Flex/Ext, flexion/extension; Abd/Add, abduction/adduction; Er/Ir, extra-/intrarotation. 